IZA DP No. 7944

Happy in the Hood?

The Impact of Residential Segregation on Self-Reported Happiness

Chris M. Herbst

Joanna Lucio

February 2014 


\title{
Happy in the Hood? The Impact of Residential Segregation on Self-Reported Happiness
}

\author{
Chris M. Herbst \\ Arizona State University \\ and IZA \\ Joanna Lucio \\ Arizona State University \\ Discussion Paper No. 7944 \\ February 2014 \\ IZA \\ P.O. Box 7240 \\ 53072 Bonn \\ Germany \\ Phone: +49-228-3894-0 \\ Fax: +49-228-3894-180 \\ E-mail: iza@iza.org
}

\begin{abstract}
Any opinions expressed here are those of the author(s) and not those of IZA. Research published in this series may include views on policy, but the institute itself takes no institutional policy positions. The IZA research network is committed to the IZA Guiding Principles of Research Integrity.

The Institute for the Study of Labor (IZA) in Bonn is a local and virtual international research center and a place of communication between science, politics and business. IZA is an independent nonprofit organization supported by Deutsche Post Foundation. The center is associated with the University of Bonn and offers a stimulating research environment through its international network, workshops and conferences, data service, project support, research visits and doctoral program. IZA engages in (i) original and internationally competitive research in all fields of labor economics, (ii) development of policy concepts, and (iii) dissemination of research results and concepts to the interested public.
\end{abstract}

IZA Discussion Papers often represent preliminary work and are circulated to encourage discussion. Citation of such a paper should account for its provisional character. A revised version may be available directly from the author. 
IZA Discussion Paper No. 7944

February 2014

\section{ABSTRACT}

\section{Happy in the Hood? The Impact of Residential Segregation on Self-Reported Happiness}

Previous research consistently finds that racially-based residential segregation is associated with poor economic, health, and social outcomes. The purpose of this paper is to explore the relationship between residential segregation and self-reported happiness. Using panel data from the National Survey of Families and Households (NSFH), we begin by estimating ordinary least squares (OLS) regressions of happiness on a measure of MSA-level segregation, controlling for a rich set of individual, neighborhood, and state characteristics. The OLS results suggest that increased segregation is associated with a reduction in happiness among blacks. To deal more appropriately with the potential endogeneity of location choice, we extend the methodology to fully exploit the panel structure of the NSFH and incorporate individual fixed effects into the happiness equation. Contrary to the OLS results, our fixed effects estimates imply that blacks are happier in more segregated metropolitan areas. The paper discusses the implications of these results within the context of current integration policies.

JEL Classification: J10

Keywords: happiness, residential segregation, neighborhood preferences

Corresponding author:

Chris M. Herbst

School of Public Affairs

Arizona State University

411 N. Central Ave., Ste. 450

Phoenix, AZ 85004-0687

USA

E-mail: chris.herbst@asu.edu 


\section{Introduction}

Segregation along racial lines remains a defining feature of U.S. metropolitan areas. Although the degree of black-white segregation has abated substantially since its peak in the mid- $20^{\text {th }}$ century, over half of blacks would still have to change neighborhoods to achieve perfect racial integration, and one-fifth continue to reside in hyper-segregated neighborhoods (Glaeser \& Vigdor, 2012). The geographic separation of blacks, and the resulting uneven distribution of resources and amenities within metropolitan areas, continues to shape public policy debates about the persistence of racial inequality in the U.S. Indeed, decades of research have been dedicated to understanding the impact of racial segregation on residents' health and well-being. In their seminal work, Massey and Denton (1993) argue that residential segregation is likely to influence individual outcomes by creating a "structural niche within which a deleterious set of attitudes and behaviors...has arisen and flourished" (p.8). In other words, by exposing its residents to high levels of crime and social disorganization, and containing fewer positive role models and external resources, segregated neighborhoods have institutionalized a culture that has negative consequences for blacks' educational attainment, marriage and labor market behavior, and health.

Using panel data from the National Survey of Families and Households (NSFH), this paper contributes new evidence on the implications of residential segregation for blacks' health and wellbeing. In particular, we draw on the first two waves of the NSFH to examine the impact of metropolitan-area (MSA) segregation on a measure of self-reported happiness. Our empirical analysis proceeds in two steps. We begin by estimating ordinary least squares (OLS) regressions of happiness on the black-white dissimilarity index, a standard measure of MSA residential segregation. Our OLS results show that increases in segregation are associated with reductions in self-reported happiness among blacks. Although we control for a rich set of individual and contextual 
characteristics, we remain concerned that the OLS estimates suffer from two sources of bias. The first is reverse causality, in which the stock of health and well-being across MSAs explains variation in segregation. The second concern deals with unobserved location preferences and human capital characteristics that are correlated with individual happiness and an area's level of segregation. To deal with these empirical challenges, we exploit the panel structure of the NSFH and introduce individual fixed effects into the model. The primary advantage of a fixed effects model is that it identifies the impact of segregation through a comparison of happiness levels when the same person is exposed to different magnitudes of residential segregation. In contrast to the OLS results, our fixed effects estimates imply that blacks' happiness increases with higher degrees of segregation. Interestingly, the black happiness boost is pronounced for prime working-age individuals, males, and those with higher levels of education.

Our investigation is important for a number of reasons. First, although definitions of happiness typically focus on the cognitive dimensions of how people feel about their lives, the wellknown connection between self-reported happiness and physical health suggests that results from this study are potentially relevant to a broad set of health outcomes (Diener \& Seligman, 2004; Frey \& Stutzer, 2002; Kahneman \& Deaton, 2011). Second, our work provides insight into individual preferences for varying degrees of residential segregation across metropolitan areas. Indeed, measures of self-reported happiness are viewed as complementary to traditional choice-based wellbeing measures (e.g., employment and income), and there is a growing body of research exploring the ways in which happiness is influenced by policy and economic phenomena, including gross domestic product and labor market conditions (Di Tella et al., 2003), gasoline prices (Boyd-Swan \& Herbst, 2012), income taxes (Akay et al., 2012), and cigarette taxes (Gruber \& Mullainathan, 2005). Implicit in this research is that observed behavior alone may not fully capture the well-being effects 
of contextual forces. Data on self-reported happiness is therefore seen as a useful supplement to choice-based welfare analysis because it is a direct measure of well-being.

Despite the potential usefulness of survey-based happiness measures, only a few previous neighborhood studies have taken advantage of them. For example, two papers examine the relative income hypothesis, that is, whether one's happiness depends in part on the income of those residing in the local area (Luttmer, 2005; Firebaugh \& Schroeder, 2009). Using the NSFH, Luttmer (2005) finds that higher earnings among neighbors-defined as those residing in the same metropolitan area-are associated with reductions in self-reported happiness. Conversely, Firebaugh and Schroeder (2009) use happiness data from the General Social Survey (GSS), matched with income at the census block level, and find that reported happiness rises with neighbors' income. More relevant to the current study is a recent paper by Ludwig and colleagues (2012) evaluating the impact of the Moving to Opportunity (MTO) program on long-run health and subjective well-being. The MTO demonstration is a multi-city housing mobility program that offered individuals in high-poverty, segregated neighborhoods the chance to move into housing located in less economically distressed neighborhoods. The authors find that adults who moved to lower-poverty neighborhoods experienced improved mental health and happiness 10 to 15 years after random assignment. The happiness effects are sizeable: a one standard deviation reduction in neighborhood poverty eliminates the happiness "gap" between individuals whose income differs by $\$ 13,000$. Thus, although the MTO results may not generalizable to an economically heterogeneous population, the findings strongly suggest that the neighborhood context has important consequences for reported happiness.

This paper proceeds as follows. Section II provides a conceptual framework for understanding the mechanisms through which residential segregation may influence happiness. Section III introduces the NSFH analysis sample and measures, while section IV discusses the 
empirical strategy and presents the OLS and fixed effects results. Section V concludes with a discussion of policy implications.

\section{Opportunity Structures Related to Neighborhood Change}

Blacks living in MSAs with varying levels of segregation face similarly different opportunity structures related to health production, social capital, labor market conditions, and neighborhood preferences. These opportunity structures serve as potential mechanisms through which residential segregation may influence self-reported happiness. Together, these mechanisms imply that the nature of the segregation-happiness link is theoretically ambiguous, and therefore is ultimately an empirical issue.

\section{Mental and Physical Health}

As mentioned above, there is a strong relationship between health and happiness; thus, insofar as segregation influences individual mental and physical health, such changes are a plausible mechanism through which segregation may ultimately affect happiness. Research on segregation and health has proliferated in recent years, with most studies finding that segregated blacks experience worse outcomes across a variety of health domains. Blacks in highly segregated neighborhoods have lower birth weight than their less segregated counterparts (Ellen, 2000), and they are more likely to be obese (Corral et. al., 2012; Chang, 2006) and have higher rates of hyper-tension (Kershaw et al., 2011). In addition, Subramanian and colleagues (2005) find that blacks living in MSAs with greater concentrations of blacks are more likely to self-report poor overall health than those living in MSAs with lower measures of black concentration.

Neighborhood attributes are likely to play a role in segregated blacks' poor health outcomes. Predominately low-income black neighborhoods are often food deserts with little to no access to major supermarkets, while at the same time having high concentrations of fast-food establishments 
(Kwate, 2008). Indeed, even after controlling for income levels, black neighborhoods tend to be located farther from supermarkets (Walker, Keane, and Burke, 2010). In addition, crime rates are higher in low-income neighborhoods, and, moreover, residents in racially segregated neighborhoods are more likely to fear for their safety (Ross \& Mirowsky, 2001; Sampson, Raudenbush \& Earls, 1997; Wilson \& Kelling, 1982). This context contributes to a decrease in outdoor activities and exercise, which in turn is associated with increases in obesity and other chronic health conditions (Bennett et al., 2007). Such negative health outcomes are likely to be exacerbated by the uneven supply of medical facilities, parks, and open spaces in segregated communities (Williams \& Collins, 2001). Finally, air quality tends to be poorer in low-income neighborhoods, which may explain the higher incidence of childhood asthma in segregated black neighborhoods (Williams \& Wright, 2009).

On balance, the evidence suggests that blacks pay steep health costs for residing in segregated neighborhoods. If health is a determinant of happiness, and neighborhood segregation has negative implications for mental and physical health, then it seems plausible that these negative health outcomes would ultimately reduce reported happiness. However, in some cases, segregation is linked to better health outcomes. For example, Nuru-Jeter and LaVeiste (2011) find that residential segregation actually buffers the deleterious health effects of neighborhood disadvantage. In particular, the authors find that the relationship between income inequality and mortality is mediated by the high levels of social cohesion that exist in segregated black communities (Nuru-Jeter \& LaVeiste, 2011). Such evidence accords with other research establishing a direct link between social capital and health. For example, Kawachi and colleagues (1996) find that the presence of strong social networks mediates the relationship between diagnoses for coronary heart disease and later survival rates. In particular, the authors' results imply that men with coronary heart disease have higher survival rates if their social network is robust. Therefore, it is plausible that health-driven 
changes in happiness might depend on the degree of social capital present in segregated neighborhoods, a mechanism to which we now turn in greater detail.

\section{Social Capital}

Residential segregation is often synonymous with social and economic isolation, particularly within urban communities, as discussed in William Julius Wilson's The Truly Disadvantaged (1987). One approach for ameliorating the negative consequences of social isolation is to alter residents' social ties through poverty deconcentration policy (Kleit \& Carnegie, 2011). One argument for deconcentrating poverty is that altering the environment may lead to enhanced economic outcomes as well as an improved social and cultural milieu (Wilson, 1987'). Therefore, blacks living in more integrated areas might experience an increase in happiness because they have access to more diverse and beneficial ties and opportunities.

On the other hand, there are classic studies citing the benefits associated with segregated communities that speak to the social cohesion present in these communities (e.g., Stack, 1974; Gans, 1962). Scholars also note the potential for increased political power among segregated minorities (Laveist, 1992; Bledsoe et al., 1995). This work is broadly supportive of the more recent finding that blacks in general may value social capital more than whites: Lee and Campbell (1999) find that blacks tend to interact with neighbors with greater regularity than whites. Moreover, there is evidence that racially and ethnically diverse neighborhoods are associated with reductions in social capital in U.S. neighborhoods (Putnam, 2007). Putnam contends that this could be due to the misconception that social bridges — or connecting with people from different groups — is similar to social bonds — or connecting with those in our own group. Even more provocative, he finds that residents in diverse neighborhoods experience declines in trust toward their own group members.

Along these lines, studies of inter-racial group conflict suggest that diversity alone is not 
sufficient for making integration work (e.g., Allport, 1954; Ashmore \& Del Boca, 1976). Although Allport's contact theory posits that exposure to different racial and ethnic groups will reduce feelings of prejudice, other studies qualify this by arguing that the theory holds only when individuals have comparable income (Wittig \& Grant-Thompson, 1998). Given the persistence of large black-white income gaps, contact alone might not resolve inter-group conflict. However, even if one assumes that blacks residing in mixed race neighborhoods are more likely to have incomes comparable to their white neighbors, theories related to self-esteem suggest that inter-group conflict may persist. According to Tajfel and Turner (1979) individuals either build up their own racial group or denigrate another group in an effort to establish superiority. If this dynamic occurs in mixed race neighborhoods, then attempts at integration will remain challenging.

\section{Economic Opportunity}

Previous studies overwhelmingly support the notion that residential segregation has harmful effects on a variety of economic outcomes. Blacks tend to have worse educational outcomes in segregated neighborhoods; for instance, high school graduation rates are lower (Culter \& Glaeser, 1997), and the black-white SAT-score gap is wider (Card \& Rothstein, 2007). In addition, segregation leads to negative effects with regard to employment and income: segregated blacks are less likely to be employed and have lower earnings (Cutler \& Glaeser, 1997; Wilson, 1999). In fact, Cutler and Glaeser (1997) estimate that a one standard deviation decrease in residential segregation would narrow the black-white gap in most economic outcomes by one-third. Previous research attributes these negative employment effects to the spatial separation of inner city blacks from suburban employment opportunities (Farley, 2006).

More recent research finds that segregation is related to a variety of other economic outcomes. Rugh and Massey (2010) find that home foreclosure rates during the Great Recession were 
substantially higher in segregated communities. The authors' instrumental variables estimates imply that a 10 percentage point increase in black segregation (as defined by the dissimilarity index) produced a 46 percent increase in the home foreclosure rate during the period 2004 to 2008 . The authors conclude that the home foreclosure crisis was exacerbated by a racialized lending process in which subprime loans were concentrated in highly segregated neighborhoods. Furthermore, in a paper exploring county-level determinants of intergenerational mobility, Chetty and colleagues (2014) find that low mobility areas are associated with high levels of residential segregation. In fact, the authors find that segregation is among the most important contextual determinants of mobility, along with school quality, the degree of social capital, and family structure.

\section{Neighborhood Preferences}

While it is logical to view self-reported happiness as an outcome associated with residential segregation, it is also possible that happiness merely reflects preferences for different neighborhood environments. Fair Housing laws, changes in demographics, and other targeted integration efforts have made considerable progress toward desegregating neighborhoods (Glaeser \& Vigdor, 2012), yet many blacks continue to live in highly segregated neighborhoods, many of which contain deleterious conditions. The racial proxy hypothesis posits that these negative neighborhood traits are what sustain segregation, in that both whites and blacks associate certain undesirable neighborhood characteristics with neighborhoods that are predominately minority (see Harris 2001; Ellen 2000a). In particular, Ellen (2000a) contends that assumptions about a neighborhood's trajectory, in which there is a growing presence of minorities, increases segregation. Recent research on the racial proxy hypothesis finds that even though there is some evidence supporting the hypothesis, there is an unexplained effect that cannot be attributed to poor quality neighborhoods, particularly among whites (Swaroop \& Krysan, 2011), lending support for the race per se hypothesis where the desire among 
whites to live in racially homogeneous areas (in-group) away from blacks (out-group) sustain segregation (Lewis, et al., 2011). Indeed, decades of neighborhood preferences research find similar race-based results for explaining the persistence of segregation (e.g., Ihlanfeldt \& Scatidi, 2004; Bobo \& Zubrinsky, 1996; Farley et al., 1978).

The consensus in the literature is that whites prefer to live in neighborhoods that are 80 percent white, while blacks prefer a more balanced neighborhood. Specifically, Krysan and Farley (2002) find that blacks self-reported a preference for neighborhoods with a 50-50 split between black and white residents, even though most respondents expressed a willingness to move only into predominately black neighborhoods. The authors conclude: "These results show a desire for integration coupled with an aversion to pioneering..." (Krysan \& Farley, 2002, p. 950). One potential explanation for the discrepancy between blacks' residential preferences and where they would actually move is the perceived backlash from their white neighbors. Indeed, Krysan and Farley (2002) find that approximately half of black respondents in their sample cited a fear of white hostility as the primary reason for their unwillingness to move into predominately white areas.

Ultimately, it is not clear whether blacks would be happier in more segregated neighborhoods. On the other hand, results from previous work imply that happiness among whites is likely to be increasing in neighborhood segregation. As previously stated, our research is well-suited for examining the differential neighborhood preferences of black and white individuals. Surveybased measures of happiness, such as that found in the NSFH, can proxy for such preferences, and can be a useful instrument for assessing the overall impact of changes in neighborhood conditions on individuals' quality of life. On the other hand, self-reported happiness cannot provide information on whether individuals would prefer to reside in another neighborhood, nor can it reveal how they feel about their neighbors in one MSA versus another. In addition, despite our attempts to understand the 
precise mechanisms through which the happiness-effects are operating (i.e., through changes in health, social capital, economic outcomes, and preferences) survey-based happiness measures are designed to capture global—or overall—well-being, as opposed to domain-specific elements of wellbeing.

\section{Data and Measures}

The happiness data for this analysis come from the National Survey of Families and Households (NSFH), a nationally representative sample of individuals ages 16 and older who are living in households and whose primary language is English or Spanish. ${ }^{1}$ The first wave of the NSFH was administered in 1987 and 1988, generating a sample of 13,007 adults through face-to-face interviews and self-administered questionnaires. A second round of data collection was initiated between 1992 and 1994, in which 10,005 respondents from the first wave were re-interviewed. ${ }^{2}$ The NSFH oversampled minority and single-parent families, as well as stepfamilies, recently married couples, and cohabitating couples. In addition to its large sample size, this survey is advantageous for our purposes because it can be merged with geographic information down to the census tract level.

To create the analysis sample, we pooled observations from the first two waves, creating a two-period panel of NSFH respondents. Following convention in the racial segregation literature, we retained white and black respondents residing in metropolitan areas (e.g., Cutler \& Glaeser, 1997; Robert \& Ruel, 2006). The boundaries of metropolitan areas coincide with the U.S. Census Bureau's definition of Metropolitan Statistical Areas (MSA), defined as high population density regions that include major cities and their adjacent urbanized areas. We also retained only those respondents with non-missing information on the happiness questionnaire item. Our analytic sample therefore includes

\footnotetext{
${ }^{1}$ Detailed information on the NSFH can be found in Sweet et al. (1988) and Sweet and Bumpass (1996).

${ }^{2}$ A third wave of the NSFH was initiated in 2001. This wave was excluded from the analysis because NSFH administrators substantially changed the criteria for inclusion in the sample.
} 
13,534 observations, of which 10,680 are white and 2,854 are black.

Our primary outcome variable is based on a standard questionnaire item tapping self-reported happiness. The NSFH happiness question was preceded by the following statement: "Next are some questions about how you see yourself and your life." The interviewer then asked: "First, taking all things together, how would you say things are these days?" Respondents provided an answer on a seven-point scale, where one is defined as "very unhappy" and seven as "very happy." Our main analyses are based on the full ordered categorization of happiness, although we conduct a number of sensitivity tests in which the item is dichotomized in a variety of ways. Results from these alternative measures are qualitatively similar to those reported here. This item measures global subjective wellbeing or happiness, in that it reflects an averaging of quality-of-life evaluations over multiple domains (Fischer 2009; Kahneman \& Deaton 2010; Kahneman et al. 1997). It is important to note that the NSFH measure is very similar to that found in widely used survey datasets. For example, since 1972 the General Social Survey has asked respondents: "Taken all together, how would you say things are these days - would you say that you are very happy, pretty happy, or not too happy?"

In light of the growing prominence of happiness research, happiness measures are undergoing increased scrutiny (e.g., Bertrand \& Mullainathan, 2001; Krueger \& Schkade, 2008). This research shows that reported happiness is highly correlated with an array of physical attributes, including laughing, smiling, and other expressions of positive affect (Frey \& Stutzer, 2002; Layard, 2005). Similarly, happy individuals are rated as such by family and friends, and they reportedly smile and display more positive emotions during social interactions (Helliwell, 2006; Kahneman \& Krueger, 2006). Indicators of physical health, including self-reported overall health status, sleep quality, and clinical measures of depression and anxiety, are also highly correlated with reported happiness (Diener et al. 2006). It is also noteworthy that happiness responds in predictable ways to changing 
life events — for example, by peaking in the year of a marriage or birth of a child — even though genes account for a significant fraction of one's happiness endowment.

In auxiliary analyses, we examine a measure of respondents' self-esteem. In particular, we draw on the following statements presented to NSFH respondents: "I feel that I'm a person of worth, at least on an equal plane with others," "On the whole, I am satisfied with myself," and "I am able to do things as well as other people." Answers to each statement range from one ("strongly agree") to five ("strongly disagree"). Following Nomaguchi and Milkie (2003), these statements are combined to create an index of self-esteem by summing over the individual response categories. The measure ranges from three to 15 , with larger values indicating higher levels of self-esteem.

The key explanatory variable in this analysis is a measure of the degree of black residential segregation in each MSA. Specifically, we capture segregation through the Dissimilarity Index (DI), which measures the level of residential unevenness between two groups (in this case, between white and black residents) within a metropolitan area. Formally, the DI is defined as:

(1) $\quad D I=\frac{\Sigma t_{i}\left|p_{i}-P\right|}{2 T P(1-P)}$, where

$t$ is the total population in the $i^{\text {th }}$ neighborhood, $T$ is the total population in the MSA, $p$ is the fraction black in the $i^{\text {th }}$ neighborhood, and $P$ is the fraction black in the MSA. ${ }^{3}$ The DI represents the percent of blacks who would have to move to a different neighborhood in order to achieve an even racial distribution within the MSA. It ranges from zero to one, with higher values indicating increased residential segregation. Our proxy for neighborhoods is the census tract, defined as a geographic area containing about 3,000 to 5,000 individuals assumed to be relatively homogenous with respect to economic and social characteristics. It is important to note that the DI varies at the MSA-level, and

\footnotetext{
${ }^{3}$ We used data from the 1990 U.S. Decennial Census (Summary Tape File 3A) to calculate the DI. These data were provided via CD ROM by Geolytics, Inc. The DI measure - along with a number of census tract characteristics — was then merged with the analysis sample by NSFH administrators through a restricted-use data agreement.
} 
therefore reflects the degree of residential segregation for an entire metropolitan area. Fortunately, the NSFH sample is sufficiently diverse geographically, with respondents living in 84 MSA's in the first wave and 208 MSA's in the second wave. ${ }^{4}$ In addition, most studies evaluating the health effects of residential segregation implicitly assume a linear relationship between the DI and health (e.g., Cutler \& Glaeser, 1997; Ellen, 2000). Our main analysis adopts this convention by entering the continuous DI measure in the regressions. ${ }^{5}$

Table 1 presents summary statistics for the full NSFH sample as well as for the sub-sets of white and black respondents. Consistent with previous work, whites score slightly higher than blacks on the measure of self-reported happiness—indicating a 0.12-point "happiness gap"—a difference that is nevertheless highly statistically significant (Herbst \& Ifcher, 2011). The black-white happiness gap is particularly evident at the top end of the happiness distribution. For example, approximately 51 percent of white respondents are in the top two categories of self-reported happiness, compared to 45 percent among black respondents. Interestingly, blacks score slightly higher than whites on the index of self-esteem, although the difference is not statistically significant. The mean value of the DI is 0.66 , indicating that two-thirds of the typical MSA's black population would need to relocate to a different census tract to achieve an even racial distribution in the urban area. There is substantial variation in the DI across MSAs, with the index taking a minimum value of 0.28 and maximum of 0.86. Table 1 also shows that white respondents are more likely to be married and less likely to be (single) never married than their black counterparts. White respondents are also less likely to be high school drop-outs and more likely to have at least a bachelor's degree. Furthermore, household

\footnotetext{
${ }^{4}$ We calculated an alternative version of the DI outlined in (1) based on county-level population counts. Results based on this measure, which are available upon request, are similar to those reported here.

${ }^{5}$ We experimented with alternative paramterizations of the DI that tested for a non-linear relationship between residential segregation and happiness. For example, we arrayed MSAs according to their DI level and then created dummy variables capturing MSAs at or below the $25^{\text {th }}$ percentile, between the $26^{\text {th }}$ and $50^{\text {th }}$ percentiles, between the $51^{\text {st }}$ and $75^{\text {th }}$ percentiles, and at or above the $76^{\text {th }}$ percentile of the DI distribution. Quintile distribution breaks are admittedly ad hoc, so we experimented with quartile and decile breaks as well. Results from this approach did not reveal strong evidence of non-linearities, so we report only the estimates for the continuous DI measure.
} 
income is over 1.5 times greater, on average, among white respondents. The final set of summary statistics in Table 1 provides a comparison of the neighborhood environment in which white and black respondents reside. The average white respondent, for example, lives in a census tract that is about seven percent black and whose median household income is nearly $\$ 36,000$ (in 1990 dollars). The comparable figures for black respondents are 56 percent and $\$ 24,000$.

\section{Empirical Implementation}

\section{Basic Model and Results}

Using individual-level survey data on subjective well-being merged with MSA-level information on residential segregation, we begin the empirical analysis by establishing the baseline relationship between the DI and self-reported happiness. In particular, we estimate versions of the following pooled cross-sectional happiness equation (e.g., Boyd-Swan \& Herbst, 2012; Gruber \& Mullainathan, 2005; Herbst, 2011):

$$
\begin{aligned}
Y^{*}{ }_{i c m s t}= & \varphi_{t}+\mu_{t}+\beta_{1} \text { black }_{\text {icmst }}+\beta_{2}\left(\text { DI }_{m t} \times \text { black }_{\text {icmst }}\right)+\beta_{3}\left(D I_{m t} \times \text { white }_{\text {icmst }}\right)+ \\
& \mathbf{X}^{\prime} \psi+\mathbf{C}^{\prime} \psi+\mathbf{S}^{\prime} \psi+\varepsilon_{i c m s t},
\end{aligned}
$$

where $i$ indexes individuals, $c$ indexes census tracts, $m$ indexes MSAs, $s$ indexes states, $t$ indexes the month and year of survey administration, and $Y^{*}$ is a continuous latent representation of the $i^{\text {th }}$ respondent's self-reported happiness, $Y$. We standardize the happiness index to have a mean of zero and a standard deviation of unity, and we estimate (2) using ordinary least squares regression (OLS). ${ }^{6}$ Given that the first two waves of the NSFH are administered over a period of five years, we incorporate a set of year dummy variables, $\varphi_{t}$, to account for unobserved temporal shocks that may

\footnotetext{
${ }^{6}$ We experiment with several other parameterizations of the happiness variable. First, we estimate the model on the full distribution of ordered responses using an ordered probit. The results are very similar to the OLS estimates using the standardized happiness measure. This is not surprising since the ordered probit produces estimates that standardize the happiness measure conditional on the right-handside controls. Our standardized OLS results, on the other hand, are not conditioned on the controls. Second, we create separate binary indicators that equal unity for those who are "very unhappy" and "very happy," representing the bottom and top ends of the happiness distribution, respectively. These outcomes are modeled using linear probability models (OLS). Results from these models show a similar pattern to that discussed in the text.
} 
influence happiness. We also add a set of month-of-interview dummy variables, $\mu_{t}$, to account for seasonal patterns in happiness.

The matrix given by $\mathbf{X}^{\prime}$ includes a number of observable determinants of happiness, such as gender, age (and age-squared), marital status, educational attainment, the presence of children in various age groups, employment status, (log of) total household income, and homeownership status. The model also accounts for a number of neighborhood- $\left(\mathbf{C}^{\prime}\right)$ and state-level $\left(\mathbf{S}^{\prime}\right)$ demographic, economic, and political characteristics that may be spuriously correlated with an MSA's residential configuration and individual happiness. The neighborhood controls - measured at the census tractlevel -include the (log of) total population, (log of) median household income, fraction black. The state-level characteristics are per capita income, maximum AFDC/TANF benefit (for a three-person family), population density, a dummy variable that equals unity if a given state has a Republican governor, and a continuous variable measuring the fraction of each state's population voting Republican in the previous Presidential election. ${ }^{7,8}$

The variable black is a binary indicator that equals unity if a given NSFH respondent is African American. The coefficient on black, $\beta_{1}$, captures the average difference in self-reported happiness between black and white respondents (i.e., the estimated black-white happiness gap). The coefficient of primary interest in equation (2) is $\beta_{2}$ on the interaction of the dissimilarity index, DI, with black. Given that the model omits the main effect on $D I, \beta_{2}$ can be interpreted as the standard deviation change in blacks' self-reported happiness as the MSA-level DI increases from zero (complete racial integration) to one (complete racial segregation). Of secondary importance is the

\footnotetext{
${ }^{7}$ Like most studies in the segregation-health literature, we omit state fixed effects from the model. Since there are few states with more than one MSA, including the state fixed effects does not leave sufficient identifying variation in the DI measure.

${ }^{8}$ With the exception of household income, rates of item non-response are not high in the NSFH. We retain observations with missing data on the demographic and census-tract level covariates by imputing a value of zero for the missings and including in the regressions separate dummy variables that equal unity if a given respondent has missing data on the covariates.
} 
parameter $\beta_{2}$ on an interaction between the DI and a binary indicator for white respondents. This coefficient is interpreted as the standard deviation change in whites' happiness as the MSA-level DI increases from zero to one. In results not reported here, we estimate a version of equation (2) that includes the main effect on $D I$ in addition to the interaction term $\left(D I_{m t} \times\right.$ black $\left._{i c m s t}\right)$. The coefficient on $D I$ in such a model measures the effect of residential segregation on white respondents (similarly captured by $\beta_{2}$ in the model above), while that on the interaction measures the differential effect of segregation on black respondents relative to their white counterparts. Given that the main effect is rarely statistically significant (and always small in magnitude)—which we will confirm by presenting $\beta_{2}$-we construct the estimating equation in a way that allows us to focus on the implications of residential segregation for black respondents.

Finally, it is important to note that the coefficient $\beta_{2}$ is identified through a cross-sectional comparison of self-reported happiness between individuals residing in MSAs at different points in the DI distribution. Although cross-sectional analyses are quite common in the segregation-health literature, estimates derived from this data structure are likely to be inconsistent because of the presence of unobserved individual or MSA characteristics that are related to happiness. We return to this issue in the next section.

Results from equation (2) are presented in Table 2. For brevity's sake, we present only the coefficient (and standard error) on black, $(D I \times$ black $)$, and $(D I \times$ white $) .{ }^{9}$ The standard errors are adjusted for arbitrary heteroskedasticity as well as MSA-level clustering. The model becomes more richly specified moving from column (1) to column (4). Specifically, column (1) includes only the controls for year- and month-of-interview; column (2) adds the demographic covariates; column (3) includes the neighborhood controls; and column (4) includes the state controls.

\footnotetext{
${ }^{9}$ Full results are available from the authors upon request.
} 
Looking at the full model [column (4)], the coefficient on black implies that black respondents score about 0.24 standard deviations (SDs) higher than whites on the happiness scale. In addition, the interaction term, DI $\times$ black, reveals that happiness among blacks decreases as MSA segregation levels increase, irrespective of the set of control variables included. Column (4) shows that blacks' happiness falls 0.32 SDs moving from MSAs with complete integration to those with complete segregation. Nevertheless, it appears that adding controls causes the coefficient on $D I \times$ black to become larger in magnitude (i.e., less negative). The estimated reduction in happiness decreases by one-third moving from the sparsest to the fullest specification. Such a pattern suggests that the OLS results are biased toward finding a negative relationship between residential segregation and happiness among blacks. We attempt to deal with this issue more convincingly in the next section. Consistent with previous work on the segregation-health link, we find that whites' well-being is not influenced by the level of residential segregation. Indeed, the coefficient on $D I \times$ white reveals that whites' happiness falls an imprecisely estimated 0.11 SDs [column (4)] moving from the least to the most segregated MSAs. ${ }^{10}$

\section{Extended Model}

There are at least two concerns associated with OLS estimates in the context of studying the segregation-health link. The first issue deals with the potential reverse causality in the relationship between segregation and health. In particular, it may be the case that MSA variation in segregation is explained by long- and short-run differences in the economic, social, and health composition of metropolitan areas. This suggests that residential segregation is in part caused by and not a cause of the stock of human and health capital within a metropolitan area. The second concern emphasizes the

\footnotetext{
${ }^{10}$ A test of the null hypothesis that $\beta_{2}(D I \times$ black $)$ and $\beta_{3}(D I \times$ white $)$ are equal in the full specification is nearly rejected at the 10 percent level $(\mathrm{p}=0.12)$, thus providing suggestive evidence that black respondents experience a larger happiness reduction than whites as segregation levels increase.
} 
possibility of unobserved endogenous location choices. Assuming there is some degree of skill- or occupation-based sorting across metropolitan areas, it is conceivable that a correlation exists between a city's level of segregation and the human capital characteristics of its residents. Another driver of endogenous location choices focuses on personality traits and preferences that lead individuals to reside in metropolitan areas that vary along such dimensions as the availability of cultural and social amenities, cost of living, public safety, diversity, climate, and other qualities. If individuals' human capital and personality characteristics are correlated with happiness, then $\beta_{2}$ will suffer from omitted variables bias as long as equation (2) does not sufficiently control for these factors.

To deal with these challenges, we extend the methodology to exploit the panel structure of the NSFH sample and incorporate individual fixed effects into the happiness equation. Formally, the fixed effects model is specified as follows:

$$
\begin{aligned}
Y_{i c m s t}^{*}= & \alpha_{i}+\varphi_{t}+\mu_{t}+\beta_{1} \text { black }_{i c m s t}+\beta_{2}\left(\text { DI }_{m t} \times \text { black }_{\text {icmst }}\right)+\beta_{3}\left(D I_{m t} \times \text { white }_{\text {icmst }}\right)+ \\
& \mathbf{X}^{\prime} \psi+\mathbf{C}^{\prime} \psi+\mathbf{S}^{\prime} \psi+\varepsilon_{i c m s t},
\end{aligned}
$$

where $\alpha$ is a parameter vector capturing a full set of individual-specific effects. The primary advantage of the fixed effects is that they control for all unobserved time-invariant individual characteristics that predict happiness and that might be correlated with the degree of segregation across MSAs. The identification of $\beta_{2}$ does not come from a cross-sectional comparison of individuals residing in different MSAs. Rather, our estimates are derived from a comparison of the same individual who resides in a different MSA in each wave, and thus is exposed to different degrees of residential segregation. The primary limitation of this method is that it does not account for sources of time-varying unobserved heterogeneity. It is possible, for example, that tastes and preferences evolve over time-leading individuals to demand different qualities of a city environment — or that individuals' stock of human or health capital changes over time in a way that 
alters residential decision-making. If left unaccounted for such characteristics may still lead to biased estimates of $\beta_{2}$ and $\beta_{3}$.

Equation (3) accounts for several key determinants of happiness that may be correlated with changes in residential location. Our choice of controls is guided by a report from Schachter (2001), which provides descriptive information on the reasons for residential moves using self-reports from the Current Population Survey. According to the report, a plurality of moves occurs for employment -related reasons, accounting for 37 percent of long-distance relocations. This finding is consistent with other work that has explored migration and employment (Bartel, 1979). A close second reason for moving is family-related reasons (27 percent), such as changes in marital status or family size. The third dominant reason is housing-related (24 percent), including changes in homeownership status or a desire to move to a higher-quality neighborhood. To deal with these potential confounders, equation (3) includes explicit controls for employment and marital statuses well as the number of people residing in the household. We also control for whether the respondent is a homeowner, and we incorporate a rich set of census tract-level controls to proxy for neighborhood quality (e.g.,median household income).

Table 3 presents the results of the extended model. Column (1) includes only the month- and year-of-interview controls as well as the individual fixed effects, while column (2) adds the full set of time-varying demographic, neighborhood, and state characteristics. In both models, the sign on the interaction terms, $D I \times$ black and $D I \times$ white, flips from negative to positive, suggesting that black and white respondents are increasingly happy in MSAs with higher levels of residential segregation. It is noteworthy that adding the full set of time-varying controls [column (2) versus column (1)] causes the magnitude of the happiness effect to increase (i.e., become more positive) for both sets of respondents. The increased magnitude of the segregation-happiness relationship in the fixed effects 
model is consistent with the pattern established by the OLS results in Table 2. Looking at the full model in column (2), we find that blacks' happiness increases 0.85 SDs moving from MSAs with complete integration to those with complete segregation. This effect is statistically significant at the 10 percent level. Happiness among white respondents increases considerably less, by 0.17 SDs, an effect that is not statistically significant.

Columns (3) and (4) of Table 3 provide a set of robustness checks by controlling for auxiliary respondent characteristics that may be correlated with self-reported happiness and MSA-level segregation. Column (3) adds a binary indicator that equals unity if a given respondent reports being in "good" or "excellent" overall health. Adding such a control is potentially important for at least two reasons. First, it is plausible that shocks to physical and mental health may catalyze changes in reported happiness as well as residential location. Second, several studies find that residential segregation itself has adverse effects on a variety of health indicators (e.g., Boettner, 2012; Ellen, 2000; Robert \& Ruel, 2006). Therefore, assuming that health and happiness are positively correlated, failing to control for respondent health could impart a downward bias on coefficients $\beta_{2}$ and $\beta_{3}$. As shown in column (3), adding the health control causes the estimated increase in blacks' happiness to grow slightly (to 0.96 SDs), proving some evidence of a downward bias in the corresponding estimate presented in column (2). The estimate for whites' happiness (0.14 SDs), on the other hand, appears to be more robust to the inclusion of the health control.

The second specification check, shown in column (4), adds a binary indicator that equals unity if a given respondent reports socializing with his/her neighbors at least several times per year. The reason for including this control is similar to that of the health control discussed above. It is reasonable to assume that sociability and related personality traits-however crudely measured by our variable - may be correlated with self-reported happiness and the propensity to move residential 
locations. Although is difficult to know a priori whether the degree of segregation in an MSA positively or negatively influences residents' sociability, it is not implausible to expect increased segregation to bolster social interactions between neighbors (Putnam, 2003). If this is the case, the coefficients $\beta_{2}$ and $\beta_{3}$ would be biased upward. As shown in column (4), the estimated effect of residential segregation on blacks' (0.84 SDs) and whites' (0.17 SDs) happiness is robust to the inclusion of the neighbor-interaction variable. Such stability is encouraging because it appears that the fixed effects are controlling sufficiently for relatively stable (unobserved) personality traits that determine happiness. However, it is important to note the possibility that our control for sociability is too coarse to capture nuanced personality characteristics.

\section{Interpretation}

The fixed effects model demonstrates that blacks' happiness increases 0.85 SDs moving from MSAs with complete integration to those with complete segregation. It remains to be seen, however, whether this relationship is economically important. One way to assess this is by calculating the income equivalence of the increase in happiness due to an increase in residential segregation. Specifically, we ask: how much income would the average black individual require in order to achieve a comparable level of well-being from the estimated increase in neighborhood segregation?

We calculate the income equivalence of a 0.12 -unit (or 12 percentage point) increase in the DI using the fixed effect estimate on DI $\times$ black in column (2) of Table 3. We use a 0.12-unit rise in the DI because it is the sample standard deviation of the dissimilarity index for blacks, as shown in Table 1. We then estimate a fixed effects regression of the happiness index on total household income and household income squared, incorporating the full set of individual and contextual controls but removing $D I \times$ white and $D I \times$ black, on the sub-set of black respondents. The coefficients on income and income squared are used to calculate the change in happiness due to a $\$ 1.00$ increase in 
household income from the black sample median. This marginal effect on income is then compared that on $D I \times$ black to produce a monetary valuation of the estimated effect of segregation on reported happiness. $^{11}$

A 0.12 -unit increase in the DI for blacks produces an increase in happiness equivalent to a $\$ 325$ rise in annual household income. Expressed in real 2012 dollars, the income equivalence is $\$ 657$ of annual income. One way to assess the relative importance of this figure is to compare it to blacks' reported household income in the NSFH. The happiness gain of $\$ 657$ corresponds to approximately two percent of blacks' median (annual) household income. Another way to benchmark the segregation effect is to calculate the income equivalence associated with the dramatic decline in metropolitan segregation over the last four decades. Glaeser and Vigdor (2012) report that the DI reached a high of 0.80 in the late-1960s before declining to 0.55 in 2010 , a drop of 0.25 -units. A decline of this magnitude implies that blacks' witnessed a reduction in happiness equivalent to \$661 in lost annual household income (\$1,336 in constant 2012 terms). This corresponds to about four percent of blacks' median income in the NSFH.

\section{Sub-Group Analyses}

In Table 4, we explore the possibility of differential effects of residential segregation across sub-groups of black and white respondents. In particular, we estimate equation (3) on stratified subsamples defined by gender, age group, educational attainment, and employment status. Column (1) presents the coefficient on $D I \times$ black, while column (2) presents the coefficient on $D I \times$ white. In addition to the fixed effects, all sub-groups analyses contain the full set of time-varying observables.

It appears that there are marked differences in the response to increased segregation between

\footnotetext{
${ }^{11}$ The coefficients on income and income squared are, respectively, 0.00000341 and -0.00000000000494 . Median household income for the black sub-sample in the NSFH is $\$ 18,284$ (averaged over both waves), as shown in Table 1. A \$1 increase in household income generates a $0.000003229(0.00000341-(2 * 0.00000000000494 * 18284))$ unit increase in happiness. To produce the annual income equivalent of a 0.12 -unit rise in segregation, the following was calculated: $0.123 *(0.00854 / 0.000003229)=\$ 325.31$.
} 
black men and women. Happiness among black men increases substantially as segregation rises (2.4 $S D$ s), while that among black women barely increases (0.54 SDs). The estimates for white men and women, on the other hand, are never large in magnitude or statistically significant. We also find evidence that younger blacks (ages 16 to 45) receive a larger happiness boost from rising segregation than do older blacks (ages 46 and over). However, it is important to note that, although the coefficient on $D I \times$ black for older blacks $(1.0 S D s)$ is not statistically significant, it is only slightly smaller in magnitude than that for younger blacks (1.2 SDs). The lack of statistical significance for the group of older blacks is explained by the larger standard error (s.e.=1.8), which is driven by lower cross-MSA mobility rates between NSFH data collection waves. Given that the identifying variation in equation (3) comes from within-person (cross-MSA) differences in segregation, fewer moves for a given group provide less identifying variation, and thus larger standard errors. The analyses by education level reveal that more highly skilled blacks - defined as those with at least some college education - respond more favorably to rising segregation than lower-skilled blacks — defined as those with no more than a high school degree (1.0 SDs compared to $0.92 S D \mathrm{~s})$. As with the age-based analyses, however, the difference is not large.

The final set of analyses estimates equation (3) separately on non-working and working respondents. Consistent with the education-based analyses, we find evidence that more highly skilled blacks — defined as those who are employed — witness a statistically significant happiness increase as segregation rises (1.1 SDs), while less-skilled blacks - defined as those who are not employedexperience a reduction in happiness $(-0.73 S D$ s), albeit one that is not statistically significant. Such results should be interpreted cautiously, however, as within-person (cross-MSA) moves are less common among the non-working, leaving less identifying variation available for this group. 


\section{Alternative Well-Being Outcome: Self-Esteem Index}

As an auxiliary analysis, Table 5 presents OLS and fixed effects results for an alternative measure of subjective well-being: self-esteem. Recall that the self-esteem index is constructed by summing the scores to three items in the NSFH: "I feel that I'm a person of worth, at least on an equal plane with others," "On the whole, I am satisfied with myself," and "I am able to do things as well as other people." Answers to each item range from one ("strongly agree") to five ("strongly disagree"). Given that self-reported happiness is reasonably highly correlated with the self-esteem index $(r=0.26)$, the estimates in Table 5 are a useful robustness check on the main results, in addition to being interesting in their own right. Columns (1) and (2) present the OLS results, while columns (3) and (4) present the fixed effects results. Columns (2) and (4) are regarded as the main results within each estimator, as these columns contain the full set of controls.

Two findings in Table 5 are noteworthy. First, as we move from the OLS to the fixed effects results, we observe a pattern unfold similar to that for the happiness results. As the model becomes more richly specified, the sign on the coefficient $D I \times$ black flips from negative (suggesting that blacks' well-being is decreasing in MSA-level segregation) to positive (suggesting that blacks' wellbeing is increasing in segregation). Indeed, as of the full fixed effects model [column (4)], it appears that black scores on the self-esteem scale increase over six points moving from MSAs with complete integration to those with complete segregation. Second, unlike the happiness models, whites' selfesteem is influenced by the level of MSA segregation. In particular, rising segregation is estimated to lower self-esteem among white respondents, an effect that increases in magnitude moving from the OLS to the fixed effect models. The estimate on DI $\times$ black in column (4) suggests that whites' scores on the self-esteem scale are lower by 1.1 point in fully segregated metropolitan areas as compared to fully integrated ones. 


\section{Conclusion}

Racial segregation is a longstanding problem in the U.S., exacerbated by discriminatory practices and attitudes as well as an unequal distribution of resources across metropolitan areas. Neighborhood preferences research suggests that the differential location preferences of whites and blacks is an important explanation for the continued presence of segregation in metropolitan areas. There has been considerable research on the implications of this geographic separation for the wellbeing of whites and blacks. The general consensus in the literature is that whites are not affected by living in areas with varying degrees of segregation. Blacks, on the other hand, appear to be negatively impacted by segregation, particularly with respect to health and economic outcomes.

This paper examines the impact of MSA-level residential segregation on self-reported happiness. Prior studies link happiness with a variety of health outcomes and, specifically, illustrate the potential of happiness measures to capture global well-being. Furthermore, such measures can provide insight into differential preferences across racial groups in a way that is not confounded by instrumentation bias. Using rich panel data from the NSFH, our baseline OLS model reveals qualitatively similar results to some recent health-related research on segregation, specifically showing that blacks are worse off in more segregated areas. However, once we extend the model to take advantage of the panel data, the results indicate that blacks in increasingly segregated MSAs are actually happier than their counterparts in less segregated MSAs. This relationship remains robust to adding controls for self-reported health and neighbor interactions, implying that the estimated segregation-health link may not operate through changes in health or social well-being. In a series of sub-group analyses, we also provide additional insight into this relationship. The rise in blacks' happiness appears to be concentrated among males, those under 46 years old, the more highly educated, and the employed. 
Our results do not suggest that segregated communities are healthier for their residents, nor do they dismiss the negative opportunity structures present in segregated communities. Rather, they provide evidence that there might be positive elements present in more segregated areas that have been overlooked in current discourse over the relative advantages of neighborhood economic and racial diversity. Although it may appear counterintuitive to find that less integrated areas are associated with increases in blacks' happiness, evidence of strong political and social capital within these communities could be what explains this relationship. It is plausible that blacks residing in segregated communities develop productive social ties that buffer against the negative health and economic outcomes. The reason for the hesitancy of blacks to "pioneer" into predominately white neighborhoods might be supported by results in this paper-blacks might not be happy in integrated areas because of persistent discrimination and diminished social capital. It is also possible that blacks experience a variety of negative mental and physical health effects from the stigma of being a minority in integrated neighborhoods, a topic about which little is known (Nuru-Jeter \& LaVeist, 2011).

Our findings accord with those from neighborhood preferences research in that blacks might be more comfortable living in segregated areas despite the presence of other negative conditions, including poor economic opportunities and worse health outcomes. The increased happiness should not be dismissed as insignificant in light of the challenges associated with residing in segregated communities. Indeed, it might be indicative of a phenomenon that has the potential to attenuate a myriad of negative consequences. Moreover, it provides some insight into what might be lacking in less segregated communities. Toward that end, our results have potentially important policy implications. Poverty deconcentration and housing mobility policies aimed at desegregating communities might consider providing individuals with support services that ease the transition into 
diverse neighborhoods, with a particular emphasis on inter-group conflict resolution. An alternative approach is to work with residents in disenfranchised segregated communities to develop programs and amenities that improve neighborhoods and that will ultimately attract diversity more organically (Imbroscio, 2008). In sum, policies aimed deconcentrating poverty might consider leveraging the strengths in segregated communities by facilitating social integration as well as physical integration.

A few caveats about the paper's methodology and results are in order. First, neighborhood segregation measured at the MSA-level has limitations in that there is not a clear understanding of the spatial distribution of residents within the MSA. Despite the potential drawbacks of the MSAlevel dissimilarity index, its widespread use is beneficial for comparing findings across studies. Second, despite a good faith effort at including variables in the fixed effects model that account for changes in residential location between waves, reasons for between-MSA mobility are varied and complex. Therefore, there is a possibility that the current paper omitted one or more important determinants of mobility that may be correlated with self-reported happiness. To the extent that such omitted factors are correlated with MSA segregation, the fixed effects estimates reported here may still be contaminated. Finally, it is also important to recognize that the NSFH was implemented in the late-1980s and early-1990s. Although there have been significant demographic and attitudinal changes over the past several decades, residential segregation persists and policies continue apace to deconcentrate poverty and diversify neighborhoods. 
Table 1: Select Summary Statistics for the NSFH Analysis Sample

\begin{tabular}{|c|c|c|c|}
\hline Variable & $\begin{array}{c}\text { Full } \\
\text { Sample }\end{array}$ & $\begin{array}{c}\text { White } \\
\text { Sub-Sample }\end{array}$ & $\begin{array}{c}\text { Black } \\
\text { Sub-Sample }\end{array}$ \\
\hline \multicolumn{4}{|l|}{ Dependent Variables } \\
\hline Self-reported happiness (range: $1-7$ ) & $\begin{array}{c}5.33 \\
(1.36)\end{array}$ & $\begin{array}{c}5.35 \\
(1.33)\end{array}$ & $\begin{array}{c}5.23 \\
(1.45)\end{array}$ \\
\hline Self-esteem index (range: $3-15$ ) & $\begin{array}{l}12.28 \\
(1.87)\end{array}$ & $\begin{array}{l}12.27 \\
(1.84)\end{array}$ & $\begin{array}{l}12.34 \\
(2.01)\end{array}$ \\
\hline \multicolumn{4}{|l|}{ Key Independent Variable } \\
\hline Dissimilarity Index & $\begin{array}{c}0.664 \\
(0.124)\end{array}$ & $\begin{array}{c}0.660 \\
(0.124)\end{array}$ & $\begin{array}{c}0.677 \\
(0.123)\end{array}$ \\
\hline \multicolumn{4}{|l|}{ Demographic Covariates } \\
\hline Age (years) & $\begin{array}{c}44.54 \\
(16.74)\end{array}$ & $\begin{array}{c}44.84 \\
(16.94)\end{array}$ & $\begin{array}{c}43.48 \\
(15.97)\end{array}$ \\
\hline Female $(\%)$ & $\begin{array}{c}0.604 \\
(0.489)\end{array}$ & $\begin{array}{c}0.590 \\
(0.492)\end{array}$ & $\begin{array}{c}0.652 \\
(0.476)\end{array}$ \\
\hline Married (\%) & $\begin{array}{c}0.533 \\
(0.499)\end{array}$ & $\begin{array}{c}0.589 \\
(0.492)\end{array}$ & $\begin{array}{c}0.333 \\
(0.471)\end{array}$ \\
\hline Single, never married (\%) & $\begin{array}{c}0.171 \\
(0.377)\end{array}$ & $\begin{array}{c}0.139 \\
(0.346)\end{array}$ & $\begin{array}{c}0.285 \\
(0.452)\end{array}$ \\
\hline Widowed (\%) & $\begin{array}{c}0.104 \\
(0.305)\end{array}$ & $\begin{array}{c}0.100 \\
(0.300)\end{array}$ & $\begin{array}{c}0.117 \\
(0.321)\end{array}$ \\
\hline Separated $(\%)$ & $\begin{array}{c}0.044 \\
(0.205)\end{array}$ & $\begin{array}{c}0.028 \\
(0.165)\end{array}$ & $\begin{array}{c}0.100 \\
(0.301)\end{array}$ \\
\hline Divorced $(\%)$ & $\begin{array}{c}0.149 \\
(0.356)\end{array}$ & $\begin{array}{c}0.144 \\
(0.351)\end{array}$ & $\begin{array}{c}0.164 \\
(0.371)\end{array}$ \\
\hline Less than high school (\%) & $\begin{array}{c}0.175 \\
(0.380)\end{array}$ & $\begin{array}{c}0.146 \\
(0.353)\end{array}$ & $\begin{array}{c}0.280 \\
(0.449)\end{array}$ \\
\hline High school $(\%)$ & $\begin{array}{c}0.364 \\
(0.481)\end{array}$ & $\begin{array}{c}0.363 \\
(0.481)\end{array}$ & $\begin{array}{c}0.366 \\
(0.482)\end{array}$ \\
\hline Some college $(\%)$ & $\begin{array}{c}0.243 \\
(0.429)\end{array}$ & $\begin{array}{c}0.243 \\
(0.429)\end{array}$ & $\begin{array}{c}0.245 \\
(0.430)\end{array}$ \\
\hline Bachelor's degree $(\%)$ & $\begin{array}{c}0.218 \\
(0.413)\end{array}$ & $\begin{array}{c}0.248 \\
(0.432)\end{array}$ & $\begin{array}{c}0.109 \\
(0.312)\end{array}$ \\
\hline Homeowner $(\%)$ & $\begin{array}{c}0.614 \\
(0.487)\end{array}$ & $\begin{array}{c}0.668 \\
(0.471)\end{array}$ & $\begin{array}{c}0.419 \\
(0.494)\end{array}$ \\
\hline Employed (\%) & $\begin{array}{c}0.618 \\
(0.486)\end{array}$ & $\begin{array}{c}0.628 \\
(0.483)\end{array}$ & $\begin{array}{c}0.580 \\
(0.494)\end{array}$ \\
\hline Household income $(\$)$ & $\begin{array}{c}39,649 \\
(43,103)\end{array}$ & $\begin{array}{c}43,239 \\
(45,511)\end{array}$ & $\begin{array}{c}25,590 \\
(27,830)\end{array}$ \\
\hline Census Tract Covariates & & & \\
\hline Percent black $(\%)$ & $\begin{array}{c}0.178 \\
(0.280)\end{array}$ & $\begin{array}{c}0.072 \\
(0.131)\end{array}$ & $\begin{array}{c}0.556 \\
(0.336)\end{array}$ \\
\hline Median household income (1990 \$s) & $\begin{array}{c}33,079 \\
(14,334)\end{array}$ & $\begin{array}{c}35,654 \\
(14,029)\end{array}$ & $\begin{array}{c}23,874 \\
(11,311)\end{array}$ \\
\hline
\end{tabular}


Table 2: OLS Estimates of the Relationship between Residential Segregation and Self-Reported Happiness

\begin{tabular}{|c|c|c|c|c|}
\hline Variable & (1) & (2) & (3) & (4) \\
\hline \multirow[t]{2}{*}{ black } & $0.162 *$ & $0.271 * * *$ & $0.270 * * *$ & $0.239 * * *$ \\
\hline & $(0.091)$ & $(0.081)$ & $(0.078)$ & $(0.080)$ \\
\hline \multirow[t]{2}{*}{$(D I \times$ black $)$} & $-0.465 * * *$ & $-0.398 * * *$ & $-0.383 * * *$ & $-0.320 * *$ \\
\hline & $(0.150)$ & $(0.142)$ & $(0.142)$ & $(0.144)$ \\
\hline \multirow[t]{2}{*}{$(D I \times$ white $)$} & -0.093 & -0.111 & $-0.128 *$ & -0.114 \\
\hline & $(0.086)$ & $(0.073)$ & $(0.077)$ & $(0.089)$ \\
\hline Time controls & Yes & Yes & Yes & Yes \\
\hline Demographic controls & No & Yes & Yes & Yes \\
\hline Neighborhood-level controls & No & No & Yes & Yes \\
\hline State-level controls & No & No & No & Yes \\
\hline Number of observations & 13,534 & 13,534 & 13,534 & 13,534 \\
\hline
\end{tabular}

Notes: Each cell reports the coefficient and standard error (in parentheses) on black, (DI $\times$ black), and (DI $\times$ white) in equation (2). Standard errors are adjusted for clustering within MSAs. See the text for a description of the variables included in each model. ***,**,* indicate statistical significance at the $0.01,0.05$, and 0.10 levels, respectively. 
Table 3: Fixed Effects Estimates of the Relationship between Residential Segregation and Self-Reported Happiness

\begin{tabular}{|c|c|c|c|c|}
\hline Variable & (1) & (2) & (3) & (4) \\
\hline$(D I \times$ black $)$ & $\begin{array}{c}0.303 \\
(0.478)\end{array}$ & $\begin{array}{c}0.854 * \\
(0.501)\end{array}$ & $\begin{array}{c}0.963 * \\
(0.512)\end{array}$ & $\begin{array}{c}0.842 * \\
(0.502)\end{array}$ \\
\hline$(D I \times$ white $)$ & $\begin{array}{c}0.135 \\
(0.231)\end{array}$ & $\begin{array}{c}0.172 \\
(0.228)\end{array}$ & $\begin{array}{c}0.135 \\
(0.224)\end{array}$ & $\begin{array}{c}0.171 \\
(0.228)\end{array}$ \\
\hline Time controls & Yes & Yes & Yes & Yes \\
\hline Demographic controls & No & Yes & Yes & Yes \\
\hline Neighborhood-level controls & No & Yes & Yes & Yes \\
\hline State-level controls & No & Yes & Yes & Yes \\
\hline Self-reported overall health & No & No & Yes & No \\
\hline Frequency of neighbor interaction & No & No & No & Yes \\
\hline Number of observations & 13,534 & 13,534 & 13,534 & 13,534 \\
\hline
\end{tabular}


Table 4: Sub-Group Analyses

\begin{tabular}{lcc}
\hline Variable & $(\mathbf{1})$ & $(\mathbf{2})$ \\
Women & $($ DI $\times$ black $)$ & $($ DI $\times$ white $)$ \\
Men & 0.542 & 0.275 \\
& $(0.560)$ & $(0.361)$ \\
& $2.373^{* *}$ & 0.058 \\
Ages 16 to 45 & $(0.985)$ & $(0.353)$ \\
& & \\
Ages 46 and over & $1.195^{* *}$ & 0.150 \\
& $(0.577)$ & $(0.259)$ \\
High school degree or less & 1.034 & $1.163^{*}$ \\
Some college or more & $(1.766)$ & $(0.618)$ \\
& & \\
& 0.919 & -0.038 \\
Not employed & $(0.772)$ & $(0.466)$ \\
& $1.023^{* *}$ & 0.085 \\
Employed & $(0.437)$ & $(0.284)$ \\
& & \\
& -0.726 & 0.555 \\
\end{tabular}

Notes: Each cell reports the coefficient and standard error (in parentheses) on $($ DI $\times$ black $)$ and $(D I \times$ white) in equation (3). Each row represents a different model, estimated on the sub-group indicated in the table. Standard errors are adjusted for clustering within MSAs. See the text for a description of the variables included in each model. ***,*** indicate statistical significance at the $0.01,0.05$, and 0.10 levels, respectively. 
Table 5: OLS and Fixed Effects Estimates of the Relationship between Residential Segregation and Self-Esteem

\begin{tabular}{|c|c|c|c|c|}
\hline Variable & $\begin{array}{l}\text { (1) } \\
\text { OLS }\end{array}$ & $\begin{array}{l}\text { (2) } \\
\text { OLS }\end{array}$ & $\begin{array}{l}3) \\
\text { FE }\end{array}$ & $\begin{array}{l}\text { (4) } \\
\text { FE }\end{array}$ \\
\hline black & $\begin{array}{l}-0.081 \\
(0.324)\end{array}$ & $\begin{array}{c}0.045 \\
(0.272)\end{array}$ & -- & -- \\
\hline$(D I \times b l a c k)$ & $\begin{array}{l}-0.023 \\
(0.429)\end{array}$ & $\begin{array}{c}0.109 \\
(0.381)\end{array}$ & $\begin{array}{l}6.693 * * \\
(2.911)\end{array}$ & $\begin{array}{l}6.666^{* *} \\
(2.804)\end{array}$ \\
\hline$(D I \times$ white $)$ & $\begin{array}{l}-0.254 \\
(0.188)\end{array}$ & $\begin{array}{l}-0.303 \\
(0.190)\end{array}$ & $\begin{array}{l}-1.212^{* *} \\
(0.583)\end{array}$ & $\begin{array}{l}-1.064 * \\
(0.621)\end{array}$ \\
\hline Time controls & Yes & Yes & Yes & Yes \\
\hline Demographic controls & No & Yes & No & Yes \\
\hline Neighborhood-level controls & No & Yes & No & Yes \\
\hline State-level controls & No & Yes & No & Yes \\
\hline Number of observations & 10,468 & 10,468 & 10,468 & 10,468 \\
\hline
\end{tabular}




\section{References}

Akay, A., Bargain, O., Dolls, M., Neumann, D., Peichl, A., \& Siegloch, S. (2012). Happy taxpayers? Income taxation and well-being. IZA Discussion Paper No. 6999. Bonn, Germany: Institute for the Study of Labor.

Allport, G. W. (1954) The Nature of Prejudice. Reading, MA: Addison-Wesley.

Ashmore, R.D., \& Del Boca, F.K. (1976). Psychological approaches to understanding intergroup conflict.In P.A. Katz (Ed.). Towards the elimination of racism New York: Pergamon Press., 73-123.

Bennett, G. G., McNeill, L. H., Wolin, K. Y., Duncan, D. T., Puleo, E., \& Emmons, K. M. (2007). Safe to walk? Neighborhood safety and physical activity among public housing residents. PLoS Medicine, 4, 10, 1599-1607.

Bertrand, M. \& Mullainathan, S. (2001). Do people mean what they say? Implications for subjective survey data. American Economic Review, 91, 67-72.

Bledsoe, T., Welch, S., Sigelman, L., \& Combs, M. (1995). Residential context and racial solidarity among African Americans. American Journal of Political Science, 39, 434-458.

Boyd-Swan, C. \& Herbst, C.M. (2012). Pain at the pump: gasoline prices and subjective well-being. Journal of Urban Economics, 72, 160-175.

Card, D. \& J. Rothstein. (2007). Racial segregation and the black-white test score gap. Journal of Public Economics, 91, 2158-2184.

Chang, V.W. (2006). Racial residential segregation and weight status among US adults. Social Science \& Medicine, 63, 1289-1303.

Chetty, R., Hendren, N., Kline, P., \& Saez, E. (2014). Where is the land of opportunity? The geography of intergenerational mobility in the United States. NBER Working Paper No. 19843. Cambridge, MA: National Bureau of Economic Research.

Collins, C.A. \& Williams, D.R. (1999). Segregation and mortality: the deadly effects of racism? Social Forum, 14, 495-523.

Corral, I., Landrine, H., Hao, Y., Zhao, L., Mellerson,J., \& Cooper, D. (2012). Residential segregation, health behavior and overweight/obesity among a national sample of African American adults. Journal of Health Psychology, 17, 371-378.

Cutler, D. \& Glaeser, E. (1997). Are ghettos good or bad? Quarterly Journal of Economics, $112,827-872$.

Di Tella, R., \& MacCulloch, R., Oswald, A. (2003). The macroeconomics of happiness.

Review of Economics and Statistics, 85, 809-827. 
Diener, E., Lucas, R., \& Scollon, C. (2006). Beyond the hedonic treadmill: Revising the adaption theory of well-being. American Psychologist, 61, 305-314.

Dreier, P., Mollenkopf , J. \& Swanstrom., T. (2005). Place Matters: Metropolitics for the Twenty-first Century. Lawrence, KS: University of Kansas Press.

Ellen, I. G. (2000a). Sharing America's neighborhoods: The prospects for stable racial integration. Cambridge, MA: Harvard University Press.

Ellen, I.E. (2000b). Is segregation bad for your health? The case of low birth weight. Brookings-Wharton Papers on urban Affairs, 203-238.

Ellen, I. G. and Turner., M.A. (1997). Does neighborhood matter? Assessing recent evidence, Housing Policy Debate, 8(4), 833-866.

Emerson, M.O., Chai, K., \& Yancey, G. (2001). Does race matter in residential segregation? Exploring the preferences of white Americans. American Sociological Review, 66, 922-923.

Farley, J. (2006). Disproportionate black and Hispanic unemployment in U.S. Metropolitan Areas: The roles of racial inequality, segregation, and discrimination in male joblessness. American Journal of Economics and Sociology, 46, 129-150.

Firebough, G. \& Shroeder, M. (2009). Does your neighbor's income affect your happiness? American Journal of Sociology, 115, 805-831.

Fischer, J. (2009). Subjective well-being as welfare measure: concepts and methodology. Munich Personal RePEc Archive Working Paper No 16619.

Freeman, L. (2005). Black homeownership: The role of temporal changes and residential segregation and the end of the $20^{\text {th }}$ Century. Social Science Quarterly, 86, 403 426.

Frey, B. \& Stutzer, A. (2002). What can economists learn from happiness research? Journal of Economic Literature, 40, 402-435.

Gans, H. J. (1962). The Urban Villagers: Group and Class in the Life of Italians-Americans. New York: Free Press of Glencoe.

Glaeser, E. \& Vigdor, J. (2012). The end of the segregated century: Racial segregation in America's neighborhoods, 1890-2010. Civic Report, Manhattan Institute, 66.

Greenbaum, S., Hathaway, W., Rodriguez, C., Spalding, A. \& Ward, B. 2008). Deconcentration and social capital: contradictions of poverty alleviation policy. Journal of Poverty, 12, 201-228.

Gruber, J. \& Mullainathan, S. (2005). Do cigarette taxes make smokers happier? Advances in Economic Analysis and Policy, 5 (Article 4). 
Harris, D. R. (2001). Why are whites and blacks averse to black neighbors? Social Science Research, 30, 100-116.

Helliwell, J. (2006). Well-being and social capital: Does suicide pose a puzzle? Social Indicators Research, 81, 455-496.

Herbst, C.M. (2012). Welfare reform and the subjective well-being of single mothers. Journal of Population Economics, 26, 203-238.

Ihlanfeldt, K. \& Scafidi, B. (2004). Whites' neighbourhood racial preferences and neighbourhood racial composition in the United States: Evidence from the multi-city study of urban inequality. Housing Studies, 19, 325-359.

Kahneman D., \& Deaton, A. (2010). High income improves evaluation of life but not emotional wellbeing. Proceedings of the National Academy of Sciences USA, 107, 1648916493.

Kahneman, D. \& Krueger, A. (2006). Developments in the measurement of subjective wellbeing. Journal of Economic Perspectives, 20, 3-24.

Kahneman D., Wakker P., \& Sarin, R. (1997). Back to Bentham? Explorations of experienced utility. Quarterly Journal of Economics, 112, 375-405.

Kawachi, I., Colditz, G.A., Ascherio, A., Rimm, E.B., Giovannucci, E., Stampfer, M.J., et al. (1996). A prospective study of social networks in relation to total mortality and cardiovascular disease in men in the USA. Journal of Epidemiology and Community Health, $50,245-251$.

Kershaw, K. N., Roux, A. V. D., Burgard, S. A., Lisabeth, L. D., Mujahid, M. S., \& Schulz, A. J. (2011). Metropolitan-level racial residential segregation and black-white disparities in hypertension. American journal of epidemiology, 174, 537-545.

Kleit, R. G., \& Carnegie, N. B. (2011). Integrated or isolated? The impact of public housing redevelopment on social network homophily. Social Networks, 33, 152-165.

Krysan, M. \& Reynolds, F. (2002). The residential preferences of Blacks: Do they explain persistent segregation? Social Forces, 80, 937-980.

Krueger, A. \& Schkade, D. (2008). The reliability of subjective well-being measures. Journal of Public Economics, 92, 1833-1845.

Kwate, N. O. A. (2008). Fried chicken and fresh apples: racial segregation as a fundamental cause of fast food density in black neighborhoods. Health \& Place, 14, 32-44.

Laveist T. A. (1993). Segregation, poverty, and empowerment: health consequences for African Americans. (1993). Milbank Quarterly, 71, 41-64. 
Laveist T. (1992). The political empowerment and health status of African-Americans: mapping anew territory. American Journal of Sociology, 97, 1080-1095.

Layard, R. (2005). Happiness: Lessons from a New Science. London: Penguin Press.

Lee, B.A. \& Campbell, K.E. (1999). Neighbor networks of black and white Americans. In Wellman (Ed.), Networks in the Global Village: Life in Contemporary Communities, Westview Press, Boulder, CO, 119-146.

Lewis, V. A., Emerson, M. O., \& Klineberg, S. L. (2011). Who we'll live with: Neighborhood racial composition preferences of Whites, Blacks and Latinos. Social forces, 89, 1385-1407.

Lipsitz, George. (1998). The Possessive Investment in Whiteness: How White People Profit from Identity Politics. Temple University Press: Philadelphia.

Logan, J.R., Stults BJ, \& Farley R. (2004). Segregation of minorities in the metropolis: Two decades of change. Demography, 41, 1-22.

Ludwig, J., Duncan, G., Gennetian, L., Katz, L., Kessler, R., Kling, J. \& Sanbonmatsu, L. (2012). Neighborhood effects on the long-term well-being of low-income adults. Science, $337,1505$.

Luttmer, E. (2005). Neighbors as negatives: Relative earnings and well-being. Quarterly Journal of Economics, 120, 963-1002.

Massey, D. S. \& Denton, N. A. (1993). American Apartheid: Segregation and the Making of the American Underclass. Cambridge, Mass.: Harvard University Press.

Massey, D.S. \& Denton, N. A. (1989). Hypersegregation in U.S. metropolitan areas: Black and Hispanic segregation along five dimensions. Demography, 26, 373-391.

Mincy, R. B. (Ed.). (2006). Black males left behind. The Urban Institute.

Meyer, S. (1999). As Long as They Don't Move Next Door: Segregation and Racial

Conflict in American Neighborhoods. Lanham, Maryland: Rowman \& Littlefield Publishers.

Nuru-Jeter, A.N. \& LaVeiste, T.A. (2011). Racial segregation, income inequality, and mortality in US metropolitan areas. Journal of Urban Health: Bulletin of the New York Academy of Medicine, 88, 270-282.

Nomaguchi, K. \& Milkie, M. (2003). Costs and rewards of children: The effects of becoming a parent on adults' lives. Journal of Marriage and Family, 65,356-374.

Putnam, R. D. (2007). E pluribus unum: Diversity and community in the twenty-first century the 2006 Johan Skytte Prize Lecture. Scandinavian political studies, 30(2), 137-174.

Robert, S. \& Ruel, E. (2006). Racial segregation and health disparities between black and white older adults. Journal of Gerontology, 61B, S203-S211. 
Robinson, J. (1980). Physical distance and racial attitudes: A further examination of the contact hypothesis. Phylon, 41, 325-332.

Ross, C. E., \& Mirowsky, J. (2001). Neighborhood disadvantage, disorder, and health. Journal of Health and Social Behavior, 42 (3), 258-276.

Rugh, J.S. \& D. S. Massey. (2010). Racial segregation and the American foreclosure crisis. American Sociological Review, 75, 629-651.

Sampson, R. J., Raudenbush, S. W., \& Earls, F. (1997). Neighborhoods and violent crime: A multilevel study of collective efficacy. Science, 277(5328), 918-924.

Schachter, J. (2001a). Geographical mobility: Population characteristics. Washington, DC: U.S. Census Bureau.

Schachter, J. (2001b). Why people moue: Exploring the March 2000 Current Population Survey. Washington, DC: U.S. Census Bureau.

Stack, C. B. (1974). All Our Kin: Strategies for Survival in a Black Community. Harper and Row.

Subramanian, S.V., Acevedo-Garcia, D., \& Osypuk, T.L. (2005). Racial residential segregation and geographic heterogeneity in black/white disparity in poor self-rated health in the US: a multilevel statistical analysis. Social Science and Medicine, 60, 1667-1679.

Swaroop, A. \& Krysan, M. (2011). The determinants of neighborhood satisfaction: Racial proxy revisited. Demography, 48, 1203-1229.

Sweet, J. \& Bumpass, L. (1996). The National Survey of Families and HouseholdsWaves 1 and 2: Data Description and Documentation. Center for Demography and Ecology, University of Wisconsin-Madison (http://www.ssc.wisc.edu/nsfh/home.htm).

Sweet, J., Bumpass, L., \& Call, V. (1988). The Design and Content of The National Survey of Families and Households. Center for Demography and Ecology, University of Wisconsin-Madison, NSFH Working Paper No. 1.

Tajfel, H., \& Turner, J. C. (1979). An integrative theory of intergroup conflict. The social psychology of intergroup relations, 33, 1-39.

VonLockette, N.D. (2010). The impact of neighborhood residential segregation on the employment chances of blacks and whites in the United States. City \& Community, 9, 256273.

Walker, R. E., Keane, C. R., \& Burke, J. G. (2010). Disparities and access to healthy food in the United States: a review of food deserts literature. Health \& Place, 16, 876-884.

Williams, D.R. \& Collins C. (2001). Racial residential segregation: a fundamental cause of racial disparities in health. Public Health Reports, 116, 404-416. 
Williams, D. R., Sternthal, M., \& Wright, R. J. (2009). Social determinants: taking the social context of asthma seriously. Pediatrics, 123(Supplement 3), S174-S184.

Wilson, W.J. (1987). The Truly Disadvantaged. University of Chicago Press: Chicago.

Wilson, W.J. (1999). When work disappears: New implications for race and urban poverty in the global economy. Ethnic \& Racial Studies, 22, 479-500.

Wilson, J. Q., \& Kelling, G. L. (1982). Broken windows. Atlantic Monthly, 249, 29-38.

Wittig, M. A. \& Grant-Thompson, S. (1998). The utility of Allport's conditions of intergroup contact for predicting perceptions of improved racial attitudes and beliefs. Journal of Social Issues, 54, 795-812. 